\title{
Analysis of Effects of Agriculture Intervention Using Propensity Score Matching
}

\author{
Peter Josephat (Corresponding author) \\ Dept. of Statistics, University of Dodoma \\ P .O. Box 338, Dodoma, Tanzania
}

Tel: 255-787-288-998Ｅ-mail: mtakwimu@yahoo.com

Rose Likangaga

Local Government Training Institute (LGTI)

P. O. Box 1125, Dodoma, Tanzania

Tel: 255-784-505-491Ｅ-mail: likangagar@yahoo.com

Received: March 29, 2015 Accepted: April 24, 2015

doi:10.5296/jas.v3i2.7339 URL: http://dx.doi.org/10.5296/jas.v3i2.7339

\begin{abstract}
Nowadays, the agriculture extension programmes are practiced in many parts of the world. There is a mixture of results about the effects of agriculture intervention programmes. The literature shows that the interventions are ineffective and have limited diffusion. On the other side, it shows that interventions are effective. Following different arguments about the effects of agriculture extension, this paper adopted Propensity Score Matching (PSM) to analyze the effects of District Agricultural Sector Investment Project (DASIP) using agriculture data.

The study was conducted in rural Tanzania areas. It covered five regions namely Kagera, Mwanza, Mara, Simiyu and Kigoma. The study focused on agro-ecological zone where corn is cultivated. Two methods which are questionnaire administration and direct oral interview were used to collect primary data. The collection of data using the questionnaire was done from both participants (359) and non-participants (519). Before running the independent t test, the estimation of propensity score was done using Logistic regression. Thirteen confounding variables were used to estimate propensity scores.
\end{abstract}


The effects of the intervention were analysed by considering four items namely the earnings from corn production, value of livestock owned, value of household assets owned, and value of farm assets owned. The results show that none of the four factors had significant result as the $\mathrm{p}$ values are greater than 0.05 . This implies that the earning between farmers participating in DASIP are not significant different from those who do not participate in the programme. The study recommends that the group activities should last longer rather than changing them from time to time.

Keywords: Agriculture Extension programme, DASIP, Farmer Field School, Intervention, Propensity Score Matching (PSM)

\section{Introduction}

The agriculture plays a major role in economic development (Yeshwanth, 2008). Nowadays, agriculture extension programmes are practiced in many parts of the world. Such programmes are implemented because farmers lack direct linkage with advanced agricultural technology. It is through extensions where farmers are given knowledge, skills and motivation for farming. These are done through Farmer Field Schools (FFS) also called Participatory Group Farmers (PGFs) model.

The FFS started in Tanzania in the 1997 (Braun et al., 2006). The approach has been engineered by both government and non-governmental organizations. The government of Tanzania adopted the FFS approach in one of its project called District Agricultural Sector Investment Project (DASIP) in which this paper is focused. The DASIP is a six year project aimed at increasing the productivity and incomes of rural households in the project area within the overall framework of the Agricultural Sector Development Strategy (ASDS). The DASIP started in the 2006.

One of the main challenges that the extension and research is currently confronted with is the transfer of agricultural technology from the research stations to the farm lands (Dinpanah et al., 2010). There is a mixture of results about the effects of agriculture intervention programmes. The literature shows that the interventions are ineffective and have limited diffusion (see Quizon et al., 2001; Feder et al., 2003; and Rola et al., 2002). On the other side, the literature shows that FFS are effective (see Godtland et al., 2004; Van den Berg., 2004; Feder et al., 2003; Tripp et al, 2005; Erickson, 2003; and Ooi et al, 2005).

There is less common rigorous impact evaluations of agricultural extension interventions despite the vast literature dealing with issues related to agricultural extension (Waddington et al., 2010). Heinrich et al. (2010) argue that this is a result of several problems accompanied by the evaluation of the programmes. The problems include: establishing the counterfactual; need for an adequate comparison group; selection bias; and role of randomization (Duflo and Kremer, 2003). These problems can be solved by the use of statistical methods depending on the nature of the intervention programmes. Unfortunately, the data used in the past impact analyses did not define well the counterfactual factors. The comparison is done by just looking at two observation points that is, before and after.

The intervention programmes can either be random or non-random. The randomized design 
occurs when the inclusion of the units or subjects in the intervention is random while non-random implies that the inclusion of the units is not by chance but depends on other factors. The randomized design programmes are very limited in literature because many intervention programmes have specific objectives and target something which makes non-random inclusion of the units. Because of this, non-experimental methods are adopted.

The Propensity Score Matching (PSM) is among the vibrant non-experimental methods. It is the most used method because it overcomes the fundamental evaluation problem and addresses the possible occurrence of selection bias. One of the advantages of this method is that it is used even if there are no baseline data. This was argued by Caliendo and Kopeinig (2005) in their working paper about guidance for the implementation of PSM.

Following different arguments about the effects of agriculture extension, this paper adopted PSM to analyse effects of DASIP using agriculture data.

\section{Material and Methods}

\subsection{Study Area}

The study was conducted in rural Tanzania particularly in the areas where DASIP operates. This covers five regions namely Kagera, Mwanza, Mara, Simiyu and Kigoma. Within these regions, the study focused on agro-ecological zone where corn is cultivated. The rationale of choosing DASIP area was that there was limited statistical survey on the impact evaluation of the programme conducted.

\subsection{Population and Sample Size}

The target population of this study was corn farmers found in DASIP intervention areas. Both DASIP participants (242,000 farmers) and non-participants were included in the study. A sampling unit was individual farmer.

Basing on the sample selection formula by Yamane (1967), out of 242,000 participant farmers, only 399 participant farmers with the precision level (margin of error) of 5\% were targeted in the sample but the study was able to include only 359 (89.97\%) participant farmers. In order to control the confounding factors, the study involved the sample of 275 (96.2\%) out of 286 non-participant farmers who were located in the villages with DASIP intervention and sample of $244(85.3 \%)$ out of targeted 286 non-participant farmers located in the villages far from villages where DASIP operates (See Table 1).

Table 1. Sample Distribution

\begin{tabular}{|l|c|c|}
\hline Corn farmer category & Targeted sample size & Actual sample size \\
\hline FFS participant farmers from villages with FFS programme & 399 & 359 \\
\hline Non-participant farmers from villages with FFS programme & 286 & 275 \\
\hline Non-participant farmers from villages without FFS programme & 286 & 244 \\
\hline Total & 971 & 878 \\
\hline
\end{tabular}

There was a need to have a large sample size of non-participant farmers in evaluating the 
impact of a programme especially PSM (Bryson et al., 2002). The PSM requires large data in both the number of variables and sample size. It is termed as a data hungry method. When data are scarce, the appropriateness of this technique should be carefully analysed (Heinrich et al., 2010). For instance, the sample size used by Lalonde (1986) consisted of 297 treatment group observation and 425 control group (Smith and Todd, 2005). Actually, the large sample makes fewer margins of error and increases confident in results.

The systematic sampling with non-equal selection probabilities was involved in the study to select the respondents. The technique was applied because the population under study was not homogenous something which restricted the use of systematic sampling with equal selection probabilities.

\subsection{Data Collection and Analysis}

The two methods namely the questionnaire administration and direct oral interview were used to collect primary data. The collection of data using the questionnaire was done from both participant (359) and non-participant farmers (519). The use of the questionnaire was preferred in this study because it is very cost-effective and it gives a greater response rate rather than adopting inadequate mailing method and/or time consuming direct oral interview in such a large sample and large geographical area. This study adopted a pre-test structured questions form of interview for safe basis generalization. The structured interview method was applied to DASIP officers.

The analysis of the effects of extension was done using an independent $t$ test. The effects of the intervention is analysed by considering four items namely the earnings from corn production, value of livestock owned, value of household assets owned, and value of farm assets owned. The earning from corn production refers the money obtained after selling corns. The value of the livestock such as chicken, guinea fowl, duck, etc. owned by the farmer comprised of the total value of all livestock. . The household assets include the total value of things such as house, mobile phone, television, radio, bicycle, etc. The farm assets include assets such as hand hoe, farm (ha), cart/barrow, plough, etc.

Before running the $\mathrm{t}$ test, the estimation of propensity score was done using Logistic regression. Thirteen confounding variables involved in estimation included: sex, age, type of farmer, marital status, level of education, household size, land owned, distance from home to corn farm $(\mathrm{km})$, distance from the village to district headquarters $(\mathrm{km})$, distance to tarmac road $(\mathrm{km})$, weather, soil type and membership of other participatory farmer groups.

\section{Results and Discussion}

\subsection{Propensity Score Matching}

Before the PSM was performed, the data were scrutinized to ensure that they are clean. The variables with outlier were cleaned. The estimated propensity score were matched using simple 1:1 nearest neighbour matching. The calliper of 0.15 of the standard deviation of the logit of the propensity score was used to exclude bad matches as recommended by Thoemmes (2012). 
In order to assess the balance achieved after matching, both univariate and multivariate balance statistics are used. For multivariate, chi square and $\mathcal{L}_{1}$ were used while for univariate standardized mean difference $|d|$ and plots were used.

The output shows that the overall chi square balance test was not significant as $\chi^{2}(13)=14.878, p=0.315$. Multivariate imbalance measure $\mathcal{L}_{1}$ for unmatched solution (before matching) was 0.998 while after matching was 0.996. Both Chi square test and multivariate imbalances show that there is no imbalance after matching. The $\mathcal{L}_{1}$ indicates that there is no imbalance because the value for matched sample is small (0.996) than unmatched sample (0.998).

For the case of univariate balance test, the standardized mean difference shows that all covariates were balanced as $|d| \leq 0.25$. The distribution of propensity scores is shown in Figure 1. The graph is visualized to examine the similarity of the propensity score distributions after matching and to assess the area of common support (Thoemmes, 2012). From Figure 1, it can be seen that there is overlapping distribution of the propensity scores in treatment and control groups as tails of histograms are overlapping.

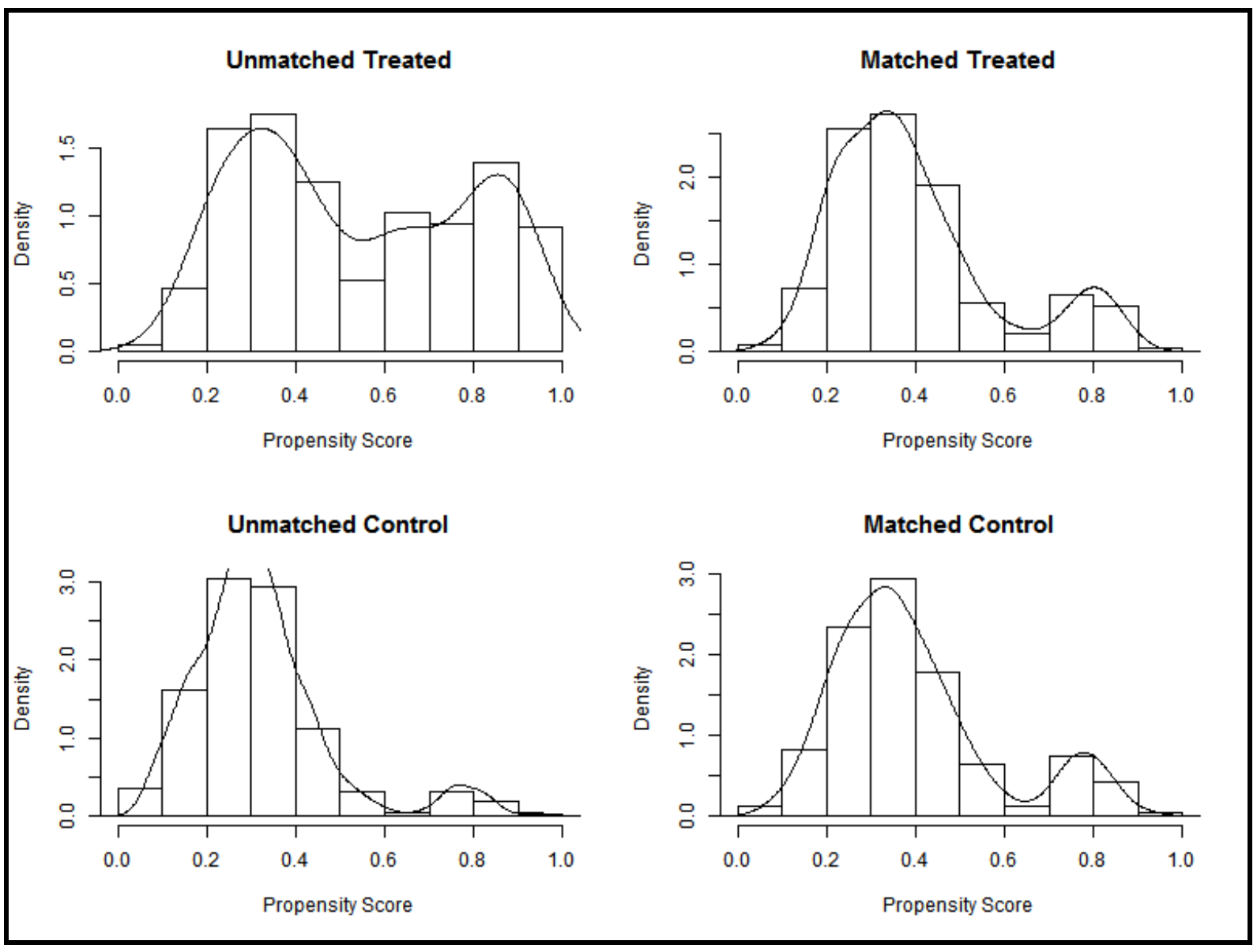

Figure 1. Distribution of Propensity Scores of Treatment and Control Groups 
In Figure 2, the plot showing individual propensity scores is presented. Unlike plot in Figure 1, Figure 2 provides information of plots of individual units. It can be easily seen that the two groups (treatment and control) are comparable.

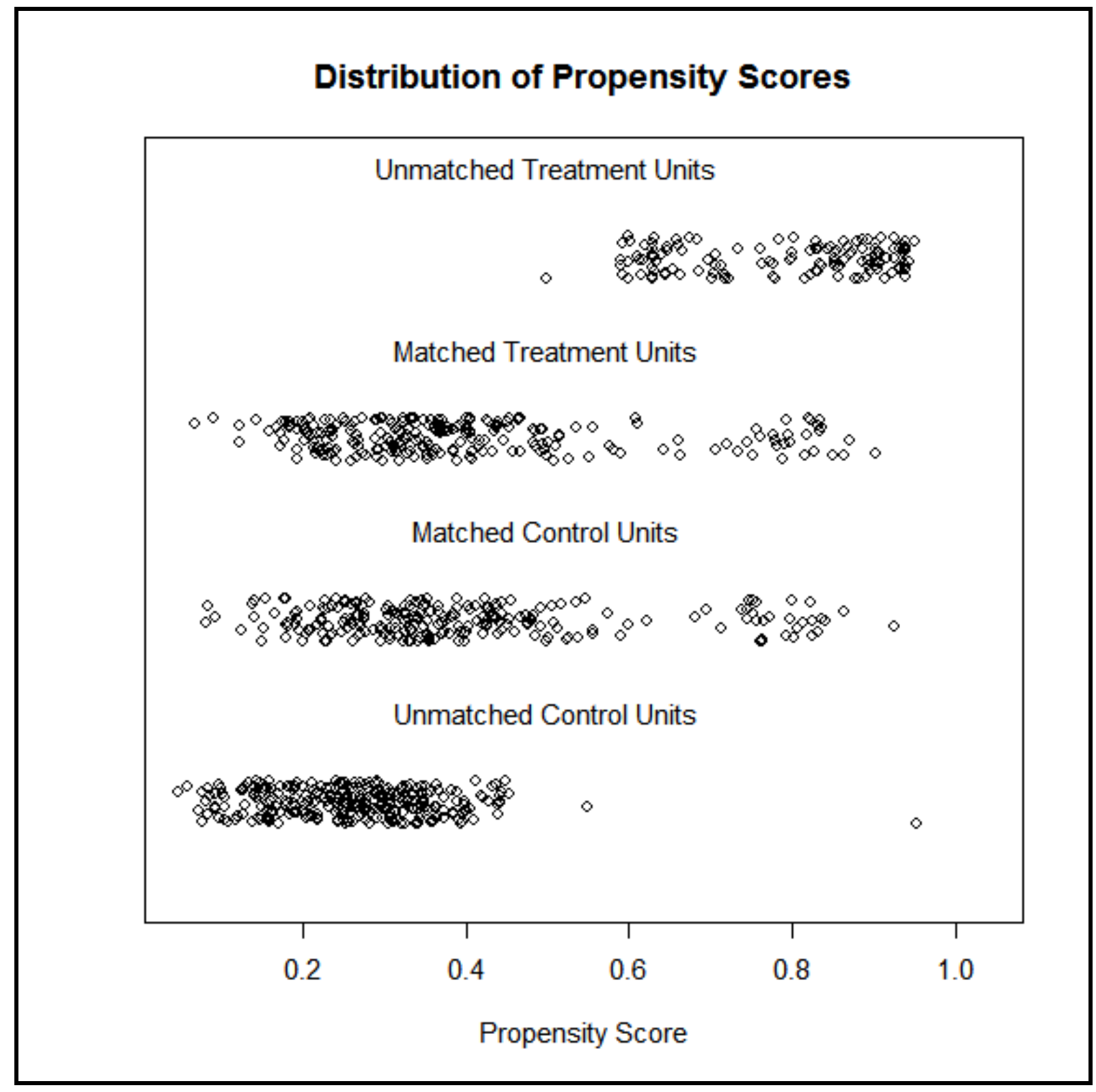

Figure 2. Dot plot of Individual Propensity Scores

The standardized difference is presented in Figure 3. From the figure, it can be seen that the standardized differences after matching are centred on zero and that no systematic difference still exist after matching. 


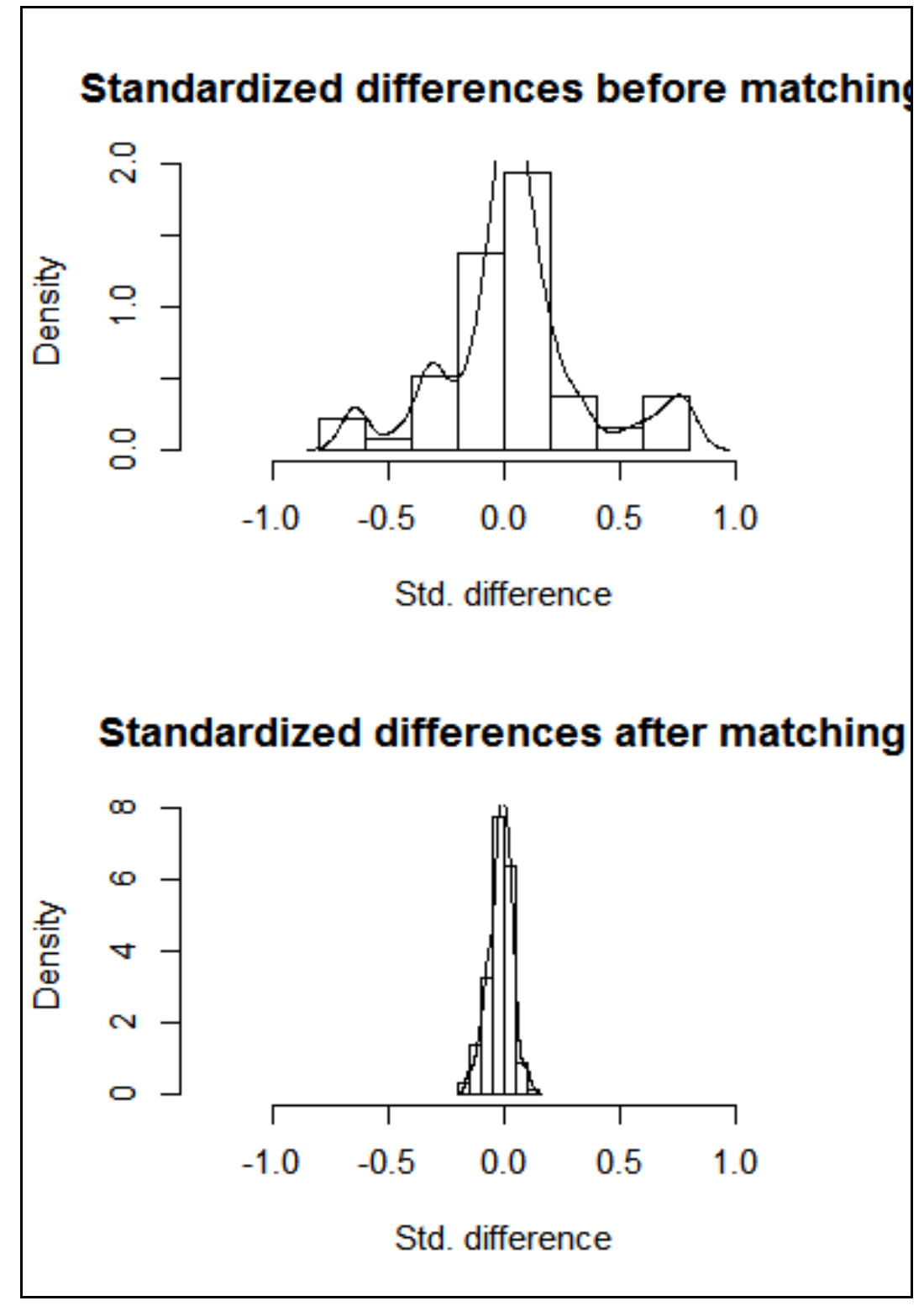

Figure 3. Histogram of Standardized Differences

The magnitude of standardized differences before and after matching for each covariate is presented in Figure 4. It can be seen from the figure that there is an improvement of scores after matching compared to before matching. 


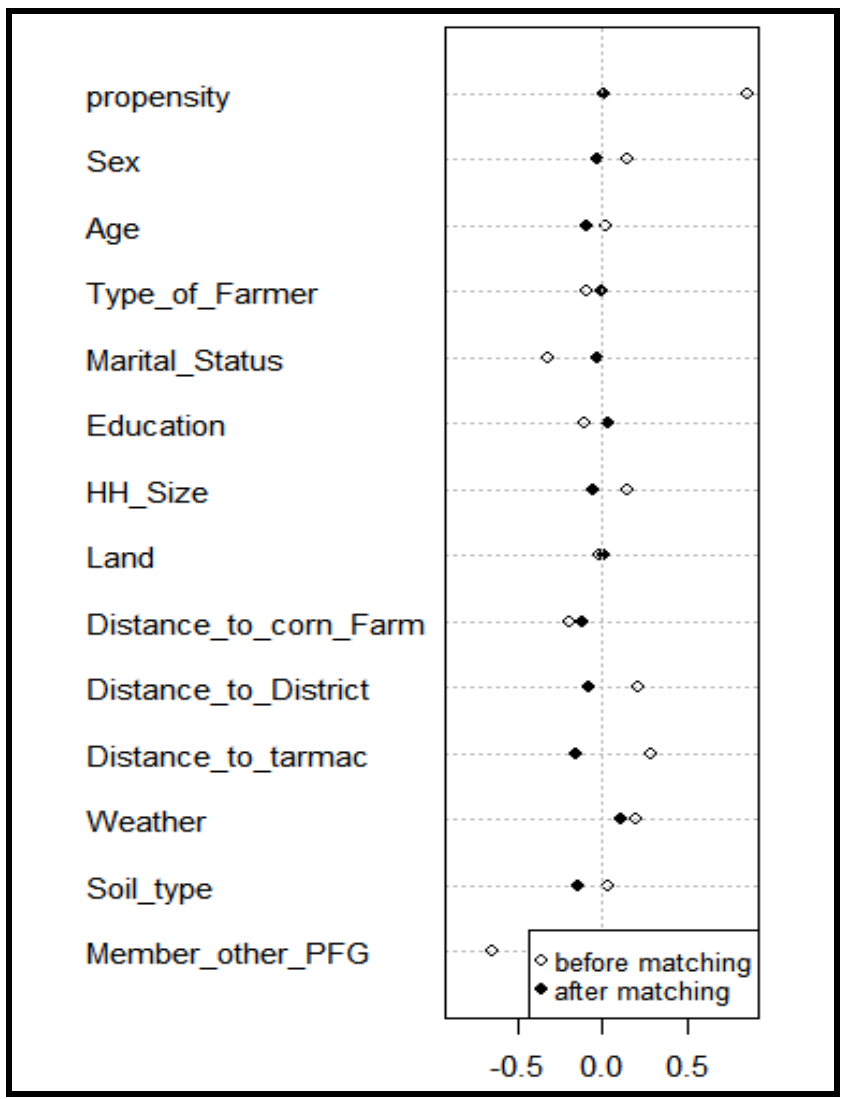

Figure 4. Dot plot of Standardized Mean Differences

In Figure 5, the standardized mean difference before and after matching are presented. The bolded lines are standardized differences that increase after matching.

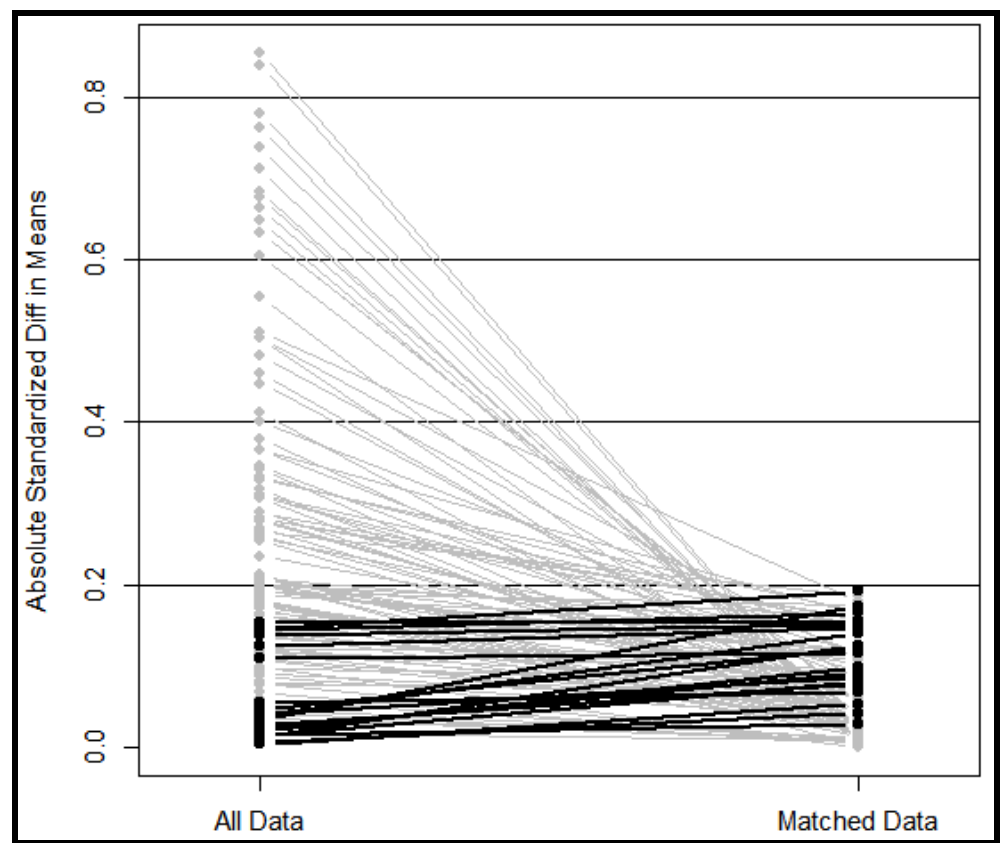

Figure 5. Line plot of Standardized Differences before and after Matching 
All the univariate and multivariate indicate that there are no imbalances after matching. Out of 878, the matched samples were 252 for both control and treated farmers. From the control group, about 265 were unmatched and 94 for treated farmers were unmatched. About 15 samples ( 2 control and 13 treated) were discarded because they were outside the common support.

\subsection{Effects of Intervention}

The $t$ test was adopted so as to compare the means of two groups (control and treatment). The test is used when the subjects are randomly assigned to two groups. Although the subjects were not randomly assigned into two groups, the adoption of PSM to some extent controls selection bias and make the difference between the groups to be due to treatment and not to other factors. The test results of the four items are presented in Table 2.

Table 2. Comparison of welfare of farmers

\begin{tabular}{|l|c|c|c|}
\hline Welfare measure & $\boldsymbol{t}$ & $\boldsymbol{d f}$ & $\boldsymbol{p}$-value \\
\hline Earnings from corn production & -1.697 & 460 & 0.090 \\
\hline Value of livestock owned & 0.824 & 460 & 0.410 \\
\hline Value of household assets owned & 0.366 & 460 & 0.715 \\
\hline Value of farm assets owned & -1.484 & 460 & 0.139 \\
\hline
\end{tabular}

None of the four factors had significant result as the $p$ values are greater than 0.05 . This implies that the earning between farmers participating in DASIP are not significant different from those who do not participate in the programme. The same applies to the other three welfare measures. Looking at the sign of $t$ values, it was found that farmers who do not participate in DASIP had high earnings from corn production compared to those participating in the programme. Also, the values of farm assets of non-participating farmers are higher than those of participant farmers. The participant farmers had higher values of livestock and household assets compared to non-participant farmers.

The findings show that DASIP has not contributed much to the welfare of farmers. This result is contrary to that obtained by Okorley et al. (2004) when studied the effects of FFS in Cocoa intervention. They find that capital assets of the farmers improved. Davis et al. (2010) find that the value of crops produced per acre, livestock value gain per capita, and agricultural income per capita increased significantly for FFS participants. The vast of the majority in literature find that FFS has improved the status of participants than non-participants. The nature and way the data were analysed is quite different to this paper. In literature, many authors focused on assessing knowledge and skills.

The results of this paper could be the results of most DASIP groups not to practice what they have acquired from DASIP. During the data collection, it was observed that groups have a tendency of changing group activities often. A group can cultivate corn this year but after just a year it can turn to be livestock keeper. There are limited groups which stick on the activities since the formation of the groups. The data were collected in rural area and average distance to district headquarter is $20 \mathrm{~km}$. 
The insignificant contribution of DASIP could be also contributed by unsatisfactory monitoring of the activities. Sometimes, the projects and activities which were performed by groups are not monitored and evaluated by the DASIP officials because of the scarcity of funds. Most of the farmers require maximum supervision in order to benefit from activities engaged. So, if there is a limited follow-up, there will be limited knowledge diffusion. Other factors such as different cultures, lack of commitment among group members, mistrust among group members, lack of water and land degradation affect both productivity and income of the farmers. A combination of all factors affects the outcome based of the four items.

\section{Conclusion}

Basing on the findings, the welfare of the farmers participating in DASIP is almost the same as that for those who do not participate in DASIP. These findings suggest that, still there is much to do with agriculture intervention in order to increase productivity. The study recommends that agriculture intervention should include a component of irrigation as one of the objectives. Also, activities performed by a group should last longer rather than changing the activities from time to time. Furthermore, there should be close monitoring and evaluation of group activities, sensitization and awareness of intervention should be advocated.

\section{Acknowledgement}

I would like to thank all my students who participated in the data collection exercise. These are Martin Dominic, Amos Justine, Sikujua Abdallah, Kway Yudathadei, Ramadhan Malimba, Masala Yohana, John Mwita, Shaban Juma and Amandus Nkenzidyo.

\section{References}

Braun, A., Jiggins, J., Röling, N., Berg, H. and Snijders, P. (2006). A Global Survey and Review of Farmer Field School Experiences. [Online] Available: http://www.ifad.org/rpr2011/background/1.pdf (August 24, 2011).

Bryson, A., Dorsett, R., \& Purdon, S. (2002). The Use of Propensity Score Matching in the Evaluation of Active Labour Market Policies. Crown.

Davis, K., Nkonya, E., Kato, E., Mekonnen, D. A., Odendo, M., Miiro, R., \& Nkuba, J. (2010). Impact of farmer field schools on agricultural productivity and poverty in East Africa. International Food Policy Research Institute (IFPRI).

Dinpanah, G., Mirdamadi, M., Badragheh, A., Sinaki, J. M., \& Aboeye, F. (2010). Analysis of Effect of Farmer Field School Approach on Adoption of Biological Control on Rice Producer' Producer' Characteristics in Iran. American-Eurasian J. Agric. \& Environ. Sci., 7 (3), 247-254.

Duflo, E., \& Kremer, M. (2003). Use of randomization in the evaluation of development effectiveness. Aper Prepared for the World Bank Operations Evaluation Development (OED) Conference on Evaluation and Development Effectiveness in Washington, DC.

Erickson, R. (2003). Review and Evaluation Technical Assistance No. 3383-PAK: Integrated 
Pest Management. Asian Development Bank. Philippines.

Feder, G., Murgai, R., \& Quizon, J. (2003). Sending farmers back to school: The impact of farmer field schools in Indonesia. Rev. Agric. Econ., 26, 1-18. http://dx.doi.org/10.1596/1813-9450-3022.

Godtland, E. M., Sadoulet, E., Janvry, A. D., \& Murgai, R. (2004), The Impact of Farmer Field Schools on Knowledge and Productivity: A study of Potato Farmers in the Perivian Andes, The Univesrty of Chicago.

Heinrich, C. Maffioli, A., \& Vázquez, G. (2010). A Primer for Applying Propensity-Score Matching: Impact-Evaluation Guidelines. Inter-American Development Bank.

LaLonde, R. J. (1986), Evaluating the Econometric Evaluations of Training Programs with Experimental Data, The American Economic Review, 76(4), 604-620.

Okorley, E. L., Adjargo G., \& Bosompem, M. (2004). The Potential of Farmer Field School in Cocoa Extension Delivery: A Ghanaian Case Study. Journal of International Agricultural and Extension Education, Volume 21, Issue 2. http://doi: 10.5191/jiaee.2014.20203.

Ooi, P. A., \& Kenmore, P. E. (2005). Impact of Educating Farmers about Biological Control in Farmer Field Schools. Second International Symposium on Biological Control of Arthropods.

Quizon, J., Feder, G., \& Murgai, R. (2001). Fiscal Sustainability of Agricultural Extension: The Case of the Farmer Field School Approach. Journal of International Agricultural and Extension Education 8(1), 13-24. http://citeseerx.ist.psu.edu/viewdoc/summa ry ?doi=10.1.1.473.3519.

Rola, A. C., S. B. Jamias, \& J. B. Quizon (2002). Do farmer field school graduates retain and share what they learn: an investigation in Iloilo, Philippines. Journal of International Agricultural and Extension Education 9: http://doi: 10.5191/jiaee.2002.09108.

Smith, J. A., \& Todd, P. E. (2005). Does matching overcome LaLonde's Critique of Non-experimental estimators? Journal of Econometrics, 125, 305-353. http://dx.doi.org/10.2139/ssrn.286297.

Thoemmes, F. (2012). Propensity score matching in SPSS. [Online] Available: http://sourceforge.net/projects/psmspss/files/ (September 12, 2014).

Tripp, R., Wijeratne, M., \& Piyadasa, V. H. (2005). What should we expect from farmer field schools? A Sri Lanka case study. World Development - Volume 33, no. 10, pp. 1705-1720. http://dx.doi.org/10.1016/j.worlddev.2005.04.012

Van den Berg, H. (2004). IPM Farmer Field Schools: A synthesis of 25 impact evaluations. Wageningen University, Report prepared for the FAO Global IPM Facility, Rome.

Waddington, H., Snilstveit, B., White, H., \& Anderson, J. (2010). The Impact of Agricultural Extension Services. International Initiative for Impact Evaluation. http://dx.doi.org/10.4102/aej.v1i1.19. 
Yeshwanth K. N. L. G. (2008). A Study on Knowledge and Adoption of Integrated Crop Management (ICM) Practices by the Participants of Farmers Field School (FFS) in Bellary District. Masters Dissertation, University of Agricultural Sciences, Dharwad.

Yamane, Taro. (1967). Statistics: An Introductory Analysis, 2nd Edition, New York: Harper and Row.

\section{Copyright Disclaimer}

Copyright for this article is retained by the author(s), with first publication rights granted to the journal.

This is an open-access article distributed under the terms and conditions of the Creative Commons Attribution license (http://creativecommons.org/licenses/by/3.0/). 